\title{
Deuterium Isotope Effects in A:T and A:U base pairs: a computational NMR study
}

Pietro Vidossich ${ }^{+o}$, Stefano Piana ${ }^{++}$, Andrea Miani $^{+}$and Paolo Carloni ${ }^{+*}$

${ }^{+}$SISSA and INFM-DEmocritos MOdeling Center for Research In aTOmistic Simulation, via Beirut 4 34014 Trieste, Italy.

${ }^{++}$Nanochemistry Research Institute, Curtin University of Technology, P.O. Box U1987, Perth 6845, Western Australia.

${ }^{\circ}$ Current Address: Parc Científic de Barcelona, C/ Josep Samitier 1-5, 08028 Barcelona.

\section{SUPPLEMENTARY INFORMATION}

\section{Classical Molecular Dynamics of DNA and RNA duplexes}

We focus on the following oligonucleotides ${ }^{1,2}:$ d1: d(CGCGAATTCGCG)2; r1: r(CGCGAAUUCGCG)2; $\quad$ d2: $\quad$ d(CGTTTTAAAACG)2; $\quad$ r2: $\quad$ r(CGUUUUAAAACG)2; $\quad$ d3: d(CGAAAATTTTCG)2; r3: r(CGAAAAUUUUCG)2. d1 is an extensively studied dodecamer. The simulation of the others allows to investigate the conformational properties of several A:T(U) pairs in a single MD simulation. Notice that the sequence $\mathbf{d 4}$, investigated in refs ${ }^{1,2}$, was not considered here because of the high number of ApT steps present, which have been reported to be poorly described by current force fields ${ }^{3}$.

Initial conformations for the duplexes were constructed with the NUCGEN module of the AMBER suite of programs ${ }^{4}$. DNA duplexes were modelled in the canonical B form, while the A form was used 
for RNA duplexes ${ }^{5}$. The duplexes were solvated with water molecules (4491 and 4990 for DNA and RNA, respectively) and $22 \mathrm{Na}+$ ions to neutralize the simulation cell.

All the calculations were performed with the GROMACS program ${ }^{6}$. The AMBER (version $99^{7 ; 8}$ ) and TIP3P $\mathrm{P}^{9}$ force fields were used for the duplex and for water, respectively. The AMBER force field has recently proven to be successful in describing DNA duplexes structure ${ }^{10}$, elastic properties ${ }^{11}$ and base pair deformability ${ }^{12 ; 13}$. All bonds were constrained using the LINCS algorithm ${ }^{14}$. A timestep of $1.5 \mathrm{fs}$ was used for all the dynamics. Periodic boundary conditions were applied. The size of the simulation cells were 46x46x67 $\AA$ and 46x49x68 $\AA$ for DNA and RNA, respectively. Long range electrostatic interactions were treated with the PME method ${ }^{15}$. A $12 \AA$ cutoff for the real part of the electrostatic and for van der Waals interactions was used. Recently, the same simulation procedure was used to investigate the relative flexibility of duplexes $\mathbf{d 1}$ and $\mathbf{r 1}$, which turn out to be in line with a statistical analysis of high resolution X-ray structures ${ }^{16 ; 17}$.

The equilibration phase for each system was as follows: i) equilibration of the solvent by performing 1 ns of MD with the duplex fixed at the initial conformation; ii) energy minimization of the system with 250 steepest descent steps followed by 250 conjugate gradient steps, while the positions of the heavy atoms of the duplex were restrained; then 500 steepest descent steps followed by 500 conjugate gradient steps were performed with no restraints; iii) 30 ps of NPT MD simulation from 0 to $10 \mathrm{~K}$ on the entire system, $20 \mathrm{ps}$ from 10 to $50 \mathrm{~K}, 20$ ps for each $50 \mathrm{~K}$ increase of temperature from $50 \mathrm{~K}$ up to 298 K. Berendsen thermostat and barostat were used to keep the above temperatures and pressure of 1 Atm ${ }^{18} \cdot \sim 10 \mathrm{~ns}$ of NPT MD simulation were carried out for each system and the last 7 ns were used for data analysis. Constant temperature $(298 \mathrm{~K})$ and pressure (1 bar) conditions were achieved by coupling the systems to a Nose-Hoover thermostat ${ }^{19 ; 20}$ and a Parrinello-Rahman barostat ${ }^{21}$, respectively, with coupling constants of $1 \mathrm{ps}$. 
Calculated properties. The following properties were calculated from the MD trajectories: i) gyration radius $\mathrm{R}_{\mathrm{g}}=\left(\Sigma_{\mathrm{I}} \mathrm{m}_{\mathrm{i}} \mathrm{r}_{\mathrm{i}}^{2} / \Sigma_{\mathrm{I}} \mathrm{m}_{\mathrm{i}}\right)^{1 / 2}$, where $\mathrm{m}_{\mathrm{i}}$ and $\mathrm{r}_{\mathrm{i}}$ are the mass and the position (with respect to the center of mass of the protein) of atom $i$, and the sum runs over all protein atoms; ii) root mean square displacement (rmsd) relative to the minimized structure $^{22}$; iii) root mean square fluctuations ${ }^{22}$; iv) distance and angle distribution of hydrogen bonds between bases in base pairs; v) Helical parameters and base pair conformations along the classical MD trajectory were analyzed with the X3DNA $\operatorname{program}^{23}$.

Results. All the duplex simulations are stable within the time scale investigated, as indicated by the radius of gyration and the RMSD with respect to the starting structure which oscillate around a constant during the dynamics (Tab. 1SI and Fig. 1SI). The root mean square fluctuations (RMSF) with respect to the average structure is a measure of the local flexibility. RMSF were calculated for each base and are reported in figure 2SI. Due to the symmetry of the duplexes investigated the values for the two strands of the same duplex should be identical. Indeed, the plots reported in figure 2SI are very similar, indicating that the sampling of the double helix conformation in MD simulations is converged. The terminal bases are generally the most flexible; amongst the internal sequences, the $\mathrm{T}$ rich regions are also remarkably flexible.

The average A:T base pair parameters calculated from the MD simulations were compared with those calculated from high resolution X-ray structures ${ }^{24}$. Figure 3SI shows that all average parameters are within 2 standard deviations from the average X-ray values, most being within 1 standard deviation. It is interesting to note that the A:U stretch value in the RNA duplexes is always larger than the average value observed in A-DNA structures ${ }^{24}$. Base pair parameters calculated from the MD simulation of duplex d1 can be compared with parameters calculated from the high resolution X-ray and NMR 
structures of the same duplex ${ }^{25-30}$. Tab. 2SI shows that the calculated values are not generally in agreement with the experimentally determined values, with only about $50 \%$ of MD average parameters being within 3 standard deviations of the X-ray average values.

\section{Electron and shielding density calculations of A:T nucleotide and base pair in the gas phase}

We have performed DFT-BLYP calculations of the charge density and shielding density of the A:T nucleotide (which includes the ribose and phosphate moieties), and the correspondent base pair in the gas phase. Based on the density differences between the two systems (Fig. 4SI), we suggest that the phosphate backbone and sugar moiety have a direct effect on the shielding at C2@A, although the extent of this feature is possibly affected by the different overall charge of the two systems and by the absence of counterions in the calculations. Thus, we cannot exclude a different contribution to the observed difference in DIE's in RNA and DNA caused by the different sugar moiety (ribose in RNA, deoxyribose in DNA) along with the different conformation (A form in RNA, B form in DNA). In addition, we notice that these moieties affect the shielding density distribution on the entire base pair. 


\section{References}

(1) Vakonakis, I.; LiWang, A. C. J.Biomol.NMR 2004, 29, 65-72.

(2) Vakonakis, I.; LiWang, A. C. J.Am.Chem.Soc. 2004, 126, 5688-5689.

(3) Sponer, J.; Leszczynski, J.; Hobza, P. Biopolymers 2001, 61, 3-31.

(4) Pearlman, D. A.; Case, D. A.; Caldwell, J. W.; Ross, W. S.; Cheatham, T. E.; Debolt, S.; Ferguson, D.; Seibel, G.; Kollman, P. Comput.Phys.Comm. 1995, 91, 1-41.

(5) Arnott, S.; Bond, P. J.; Selsing, E.; Smith, P. J. C. Nucleic Acids Res. 1976, 3, 2459-2470.

(6) Berendsen, HJC, Van der spoel, D, and Vandrunen, R. Comput.Phys.Comm. 91, 43-56. 1995. Ref Type: Generic

(7) Cornell, W. D.; Cieplak, P.; Bayly, C. I.; Gould, I. R.; Merz, K. M., Jr.; Ferguson, D. M.; Spellmeyer, D. C.; Fox, T.; Caldwell, J. W.; Kollman, P. A. J. Am. Chem. Soc. 1995 , 117, 5179-5197.

(8) Cheatham, T. E.; Cieplak, P.; Kollman, P. A. J. Biomol. Struct. Dyn.1999, 16, 845-862.

(9) Jorgensen, W. L.; Chandrasekhar, J. D.; Madura, J. D.; Impey, R. W.; Klein, M. L. J.Chem.Phys. 1983, 79, 926-935.

(10) Dornberger, U.; Spackovj, N.; Walter, A.; Gollmick, F. A.; Sponer, J.; Fritzsche, H. J.Biomol.Struct.Dyn. 2001, 19, 159-174.

(11) Lankas, F.; Sponer, J.; Hobza, P.; Langowski, J. J.Mol.Biol. 2000, 299, 695-709.

(12) Lankas, F.; Sponer, J.; Langowski, J.; Cheatham, T. E., III J.Am.Chem.Soc. 2004, 126, 41244125.

(13) Lankas, F.; Sponer, J.; Langowski, J.; Cheatham, T. E., III Biophys.J. 2003, 85, 2872-2883.

(14) Hess, B.; Bekker, H.; Berendsen, H. J. C.; Fraaije, J. G. E. M. J.Comput.Chem. 1997, 18, $1463-$ 1472.

(15) Essman, U.; Perera, L.; Berkowitz, M. L.; Darden, T.; Lee, H.; Pedersen, L. G. J.Chem.Phys. 1995, 103, 8577-8593.

(16) Perez, A.; Noy, A.; Lankas, F.; Luque, F. J.; Orozco, M. Nucleic Acids Res. 2004, 32, 61446151.

(17) Noy, A.; Perez, A.; Lankas, F.; Luque, F. J.; Orozco, M. J.Mol.Biol. 2004, 343, 627-638.

(18) Berendsen H.J.C; Postma J.P.M.; van Gunsteren W.F.; DiNola A; Haak J.R. J.Chem.Phys. 1984, 81, 3684-3690. 
(19) Nose', S. J. J.Chem.Phys. 1984, 81, 511-519.

(20) Hoover W.G. Phys.Rev.A 1985, 31, 1695-1697.

(21) Parrinello, M.; Rahman, A. J.Appl.Phys. 1981, 52, 7182-7190.

(22) Leach, A. R. Molecular Modelling. 2001. Pearson Education Limited. Harlow, Essex.

(23) Lu, X. J.; Olson, W. K. Nucleic Acids Res. 2003, 31, 5108-5121.

(24) Olson, W. K.; Bansal, M.; Burley, S. K.; Dickerson, R. E.; Gerstein, M.; Harvey, S. C.; Heinemann, U.; Lu, X. J.; Neidle, S.; Shakked, Z.; Sklenar, H.; Suzuki, M.; Tung, C. S.; Westhof, E.; Wolberger, C.; Berman, H. M. J.Mol.Biol. 2001, 313, 229-237.

(25) Drew, H. R.; Wing, R. M.; Takano, T.; Broka, C.; Tanaka, S.; Itakura, K.; Dickerson, R. E. P.Natl.Acad.Sci.USA. 1981, 78, 2179-2183.

(26) Shui, X. Q.; Sines, C. C.; McFail-Isom, L.; VanDerveer, D.; Williams, L. D. Biochemistry 1998, 37, 16877-16887.

(27) Shui, X. Q.; McFail-Isom, L.; Hu, G. G.; Williams, L. D. Biochemistry 1998, 37, 8341-8355.

(28) Holbrook, S. R.; Dickerson, R. E.; Kim, S. H. Acta Crystallogr.B-Stru. 1985, 41, 255-262.

(29) Westhof, E. J.Biomol.Struct.Dyn. 1987, 5 , 581-600.

(30) Wu, Z. G.; Delaglio, F.; Tjandra, N.; Zhurkin, V. B.; Bax, A. J.Biomol.NMR 2003, 26, 297-315. 
Table 1SI. Average radius of gyration of each duplex (standard deviations in parentheses).

\begin{tabular}{|l|l|}
\hline Duplex & Radius of gyration $(\mathbf{n m})$ \\
\hline $\mathrm{d} 1$ & $1.34(0.02)$ \\
\hline $\mathrm{d} 2$ & $1.35(0.02)$ \\
\hline $\mathrm{d} 3$ & $1.35(0.02)$ \\
\hline $\mathrm{r} 1$ & $1.31(0.03)$ \\
\hline $\mathrm{r} 2$ & $1.28(0.03)$ \\
\hline $\mathrm{r} 3$ & $1.32(0.03)$ \\
\hline
\end{tabular}


Table 2SI. Average base pair parameters (standard deviations in parentheses) from x-ray ${ }^{25-29}$ (first line) and $\mathrm{NMR}^{30}$ (second line) structures and MD simulation (third line) for each base pair in duplex $\mathbf{d 1}$.

\begin{tabular}{|c|c|c|c|c|c|c|}
\hline & Shear & Stretch & Stagger & Buckle & Propeller & Opening \\
\hline \multirow[t]{3}{*}{ Base pair 1} & $0.05(0.32)$ & $-0.21(0.06)$ & $0.10(0.04)$ & $4.28(1.48)$ & $-15.32(2.13)$ & $-1.92(1.95)$ \\
\hline & $0.35(0.05)$ & $-0.52(0.02)$ & $-0.36(0.03)$ & $-8.05(1.32)$ & $-17.90(0.51)$ & $1.39(1.04)$ \\
\hline & $0.19(0.30)$ & $-0.15(0.11)$ & $-0.02(0.47)$ & $3.88(14.25)$ & $-13.79(11.12)$ & $-0.19(3.73)$ \\
\hline \multirow[t]{3}{*}{ Base pair 2} & $-0.16(0.12)$ & $-0.29(0.07)$ & $0.38(0.19)$ & $2.65(6.55)$ & $-11.82(1.85)$ & $-3.45(1.22)$ \\
\hline & $-0.14(0.03)$ & $-0.34(0.03)$ & $0.35(0.03)$ & $-2.04(1.07)$ & $-14.55(1.14)$ & $0.85(0.14)$ \\
\hline & $-0.13(0.26)$ & $-0.16(0.10)$ & $0.20(0.33)$ & $-1.98(8.74)$ & $-9.21(7.59)$ & $-1.26(2.97)$ \\
\hline \multirow[t]{3}{*}{ Base pair 3} & $0.19(0.10)$ & $-0.17(0.08)$ & $0.23(0.07)$ & $-5.76(1.47)$ & $-5.01(1.41)$ & $-0.30(1.34)$ \\
\hline & $0.41(0.08)$ & $-0.47(0.04)$ & $-0.05(0.11)$ & $-3.69(0.43)$ & $-14.18(1.53)$ & $0.81(1.09)$ \\
\hline & $0.08(0.26)$ & $-0.13(0.10)$ & $0.15(0.32)$ & $-3.72(8.46)$ & $-1.92(7.68)$ & $-0.86(2.88)$ \\
\hline \multirow[t]{3}{*}{ Base pair 4} & $-0.48(0.21)$ & $-0.30(0.17)$ & $-0.13(0.10)$ & $8.65(1.53)$ & $-8.99(1.14)$ & $0.81(2.89)$ \\
\hline & $-0.19(0.08)$ & $-0.39(0.02)$ & $0.01(0.04)$ & $0.32(0.35)$ & $-13.36(1.10)$ & $-1.26(0.98)$ \\
\hline & $-0.10(0.26)$ & $-0.12(0.11)$ & $0.04(0.36)$ & $9.90(11.26)$ & $-3.82(8.13)$ & $-0.03(3.08)$ \\
\hline \multirow[t]{3}{*}{ Base pair 5} & $0.11(0.12)$ & $-0.14(0.05)$ & $0.03(0.08)$ & $5.28(1.09)$ & $-15.83(1.01)$ & $1.48(1.64)$ \\
\hline & $-0.20(0.05)$ & $-0.27(0.05)$ & $-0.18(0.04)$ & $-3.89(0.31)$ & $-19.64(0.14)$ & $-1.13(0.76)$ \\
\hline & $0.14(0.24)$ & $-0.08(0.11)$ & $-0.04(0.37)$ & $8.49(9.36)$ & $-16.16(6.93)$ & $-0.27(4.89)$ \\
\hline \multirow[t]{3}{*}{ Base pair 6} & $0.06(0.11)$ & $-0.04(0.06)$ & $0.12(0.03)$ & $2.07(1.12)$ & $-16.83(1.54)$ & $4.67(2.13)$ \\
\hline & $-0.06(0.01)$ & $-0.23(0.06)$ & $-0.24(0.05)$ & $-1.81(0.83)$ & $-22.94(0.17)$ & $-2.76(0.55)$ \\
\hline & $0.11(0.24)$ & $-0.09(0.11)$ & $0.05(0.36)$ & $2.74(8.45)$ & $-19.40(6.67)$ & $-0.06(4.88)$ \\
\hline \multirow[t]{3}{*}{ Base pair 7} & $0.13(0.15)$ & $-0.08(0.12)$ & $0.06(0.09)$ & $0.24(1.00)$ & $-17.06(0.46)$ & $4.69(1.88)$ \\
\hline & $0.07(0.02)$ & $-0.24(0.06)$ & $-0.24(0.05)$ & $1.76(0.77)$ & $-22.96(0.10)$ & $-2.68(0.64)$ \\
\hline & $-0.11(0.25)$ & $-0.09(0.11)$ & $0.07(0.36)$ & $-3.10(8.38)$ & $-19.42(6.59)$ & $-0.34(4.94)$ \\
\hline \multirow[t]{3}{*}{ Base pair 8} & $0.06(0.17)$ & $-0.20(0.11)$ & $-0.03(0.07)$ & $-0.97(0.83)$ & $-16.86(1.11)$ & $1.77(2.16)$ \\
\hline & $0.20(0.05)$ & $-0.27(0.06)$ & $-0.19(0.05)$ & $3.97(0.47)$ & $-19.47(0.35)$ & $-1.00(0.99)$ \\
\hline & $-0.14(0.25)$ & $-0.08(0.11)$ & $-0.04(0.37)$ & $-8.81(9.36)$ & $-16.48(6.58)$ & $-0.84(4.78)$ \\
\hline \multirow[t]{3}{*}{ Base pair 9} & $0.15(0.10)$ & $-0.14(0.17)$ & $-0.01(0.19)$ & $-11.43(2.85)$ & $-12.82(2.93)$ & $-0.47(1.05)$ \\
\hline & $0.18(0.07)$ & $-0.39(0.02)$ & $0.03(0.03)$ & $-0.34(0.19)$ & $-13.31(1.03)$ & $-1.33(0.92)$ \\
\hline & $0.10(0.26)$ & $-0.12(0.10)$ & $0.04(0.35)$ & $-10.58(10.52)$ & $-4.07(8.15)$ & $-0.28(3.00)$ \\
\hline \multirow[t]{3}{*}{ Base pair 10} & $-0.05(0.07)$ & $-0.20(0.15)$ & $0.22(0.09)$ & $3.88(1.46)$ & $-5.15(2.72)$ & $0.41(3.08)$ \\
\hline & $-0.40(0.07)$ & $-0.46(0.03)$ & $-0.05(0.08)$ & $3.72(0.53)$ & $-14.32(1.57)$ & $0.77(0.88)$ \\
\hline & $-0.10(0.26)$ & $-0.13(0.10)$ & $0.17(0.32)$ & $2.43(8.75)$ & $-2.97(7.82)$ & $-0.80(2.91)$ \\
\hline \multirow[t]{3}{*}{ Base pair 11} & $0.09(0.14)$ & $-0.22(0.11)$ & $0.44(0.13)$ & $-3.07(1.87)$ & $-16.78(1.03)$ & $-4.06(1.49)$ \\
\hline & $0.15(0.01)$ & $-0.34(0.02)$ & $0.35(0.01)$ & $2.12(0.62)$ & $-14.59(0.85)$ & $0.77(0.21)$ \\
\hline & $0.12(0.26)$ & $-0.16(0.10)$ & $0.19(0.34)$ & $0.52(9.03)$ & $-7.45(8.19)$ & $-1.15(2.96)$ \\
\hline \multirow[t]{3}{*}{ Base pair 12} & $-0.23(0.18)$ & $-0.16(0.08)$ & $0.25(0.11)$ & $5.68(1.45)$ & $-4.19(5.16)$ & $-3.25(1.32)$ \\
\hline & $-0.34(0.05)$ & $-0.52(0.04)$ & $-0.35(0.08)$ & $8.06(0.92)$ & $-17.86(0.56)$ & $1.37(0.98)$ \\
\hline & $-0.18(0.30)$ & $-0.14(0.11)$ & $-0.01(0.47)$ & $-1.49(15.16)$ & $-11.83(11.68)$ & $-0.31(3.66)$ \\
\hline
\end{tabular}




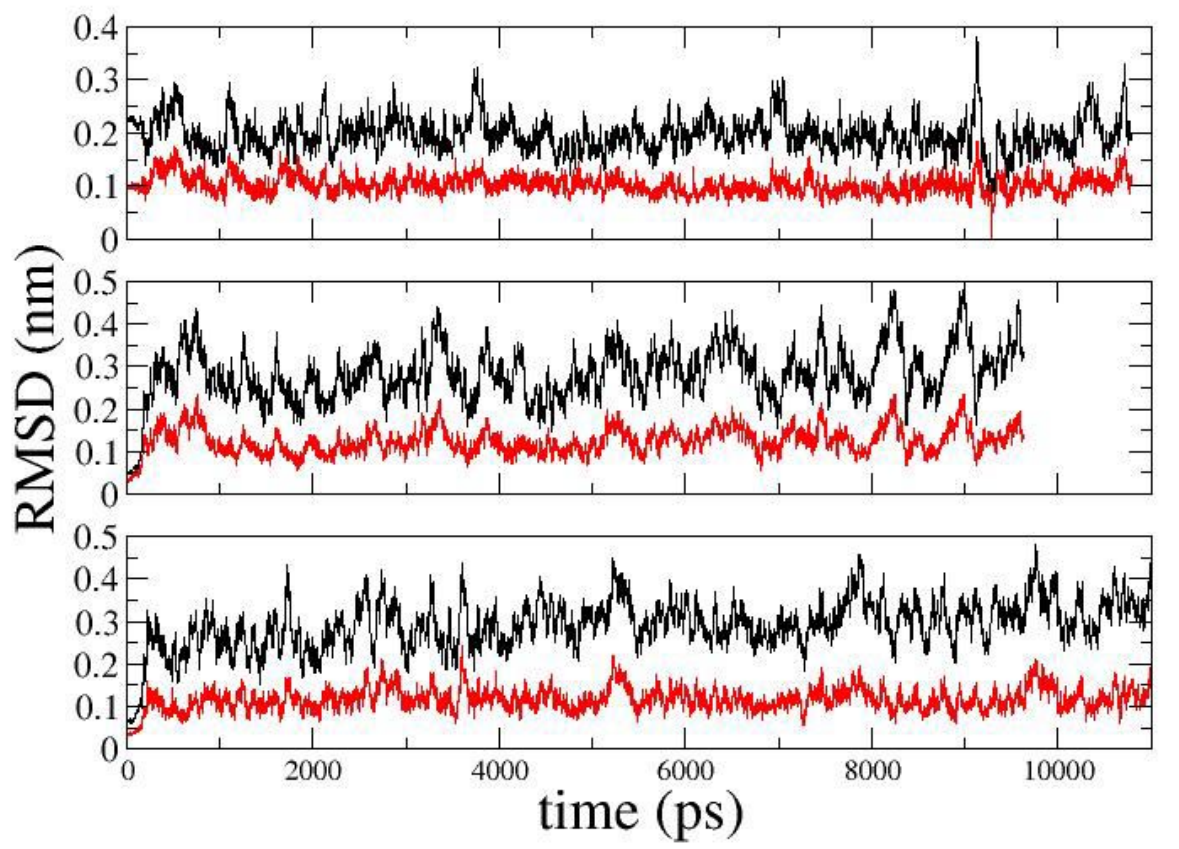

d1

d2

d3

\section{RNA duplexes}

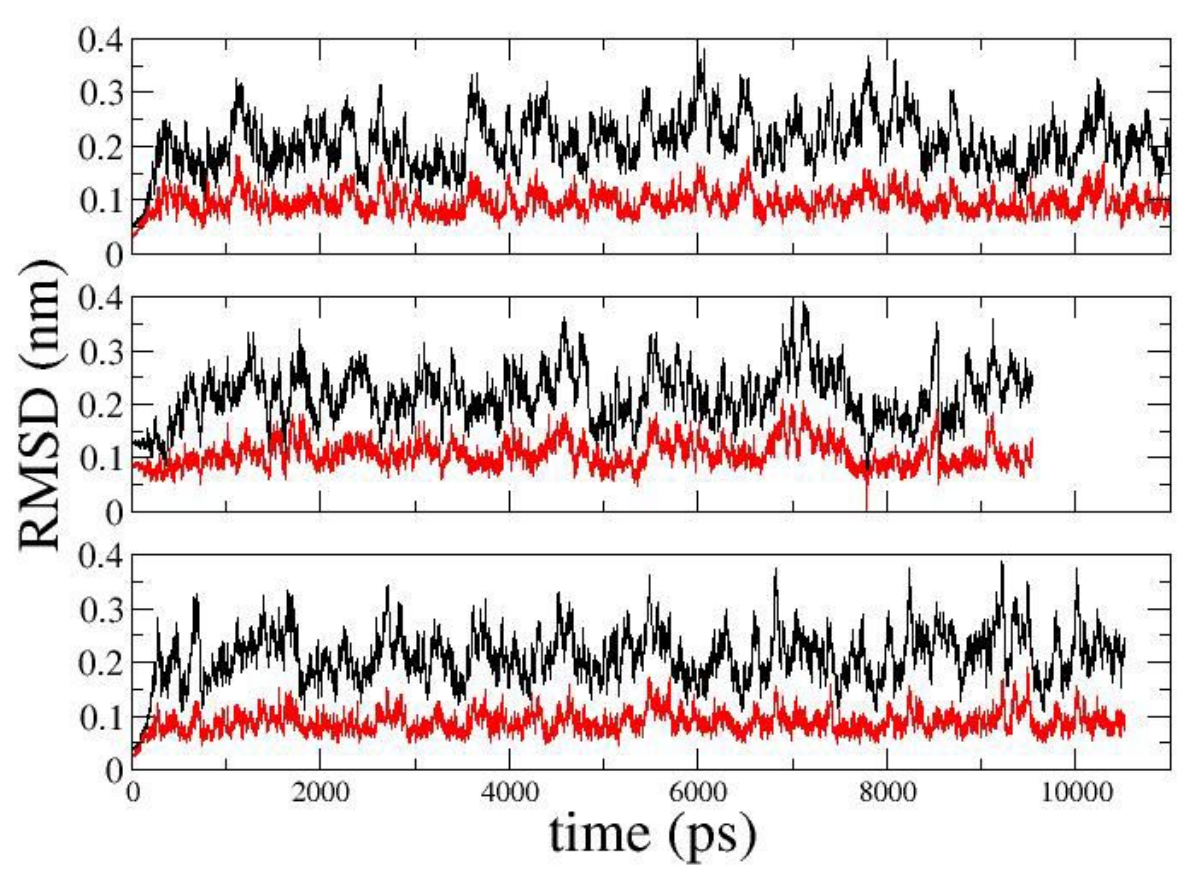

$\mathbf{r} 1$

Figure 1SI. RMSD for backbone atoms (black line) and atoms in base pairs 3 to 10 (red line) for each duplex investigated. 
DNA duplexes

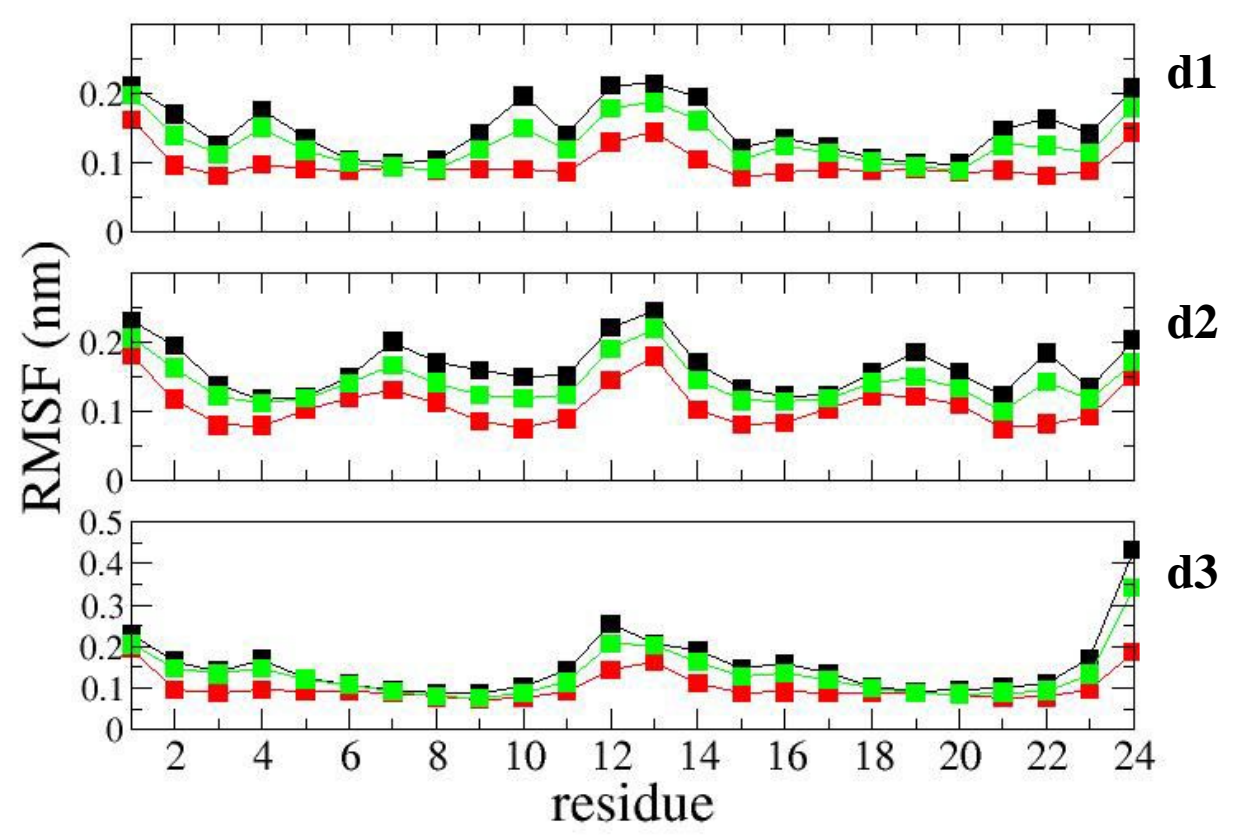

RNA duplexes

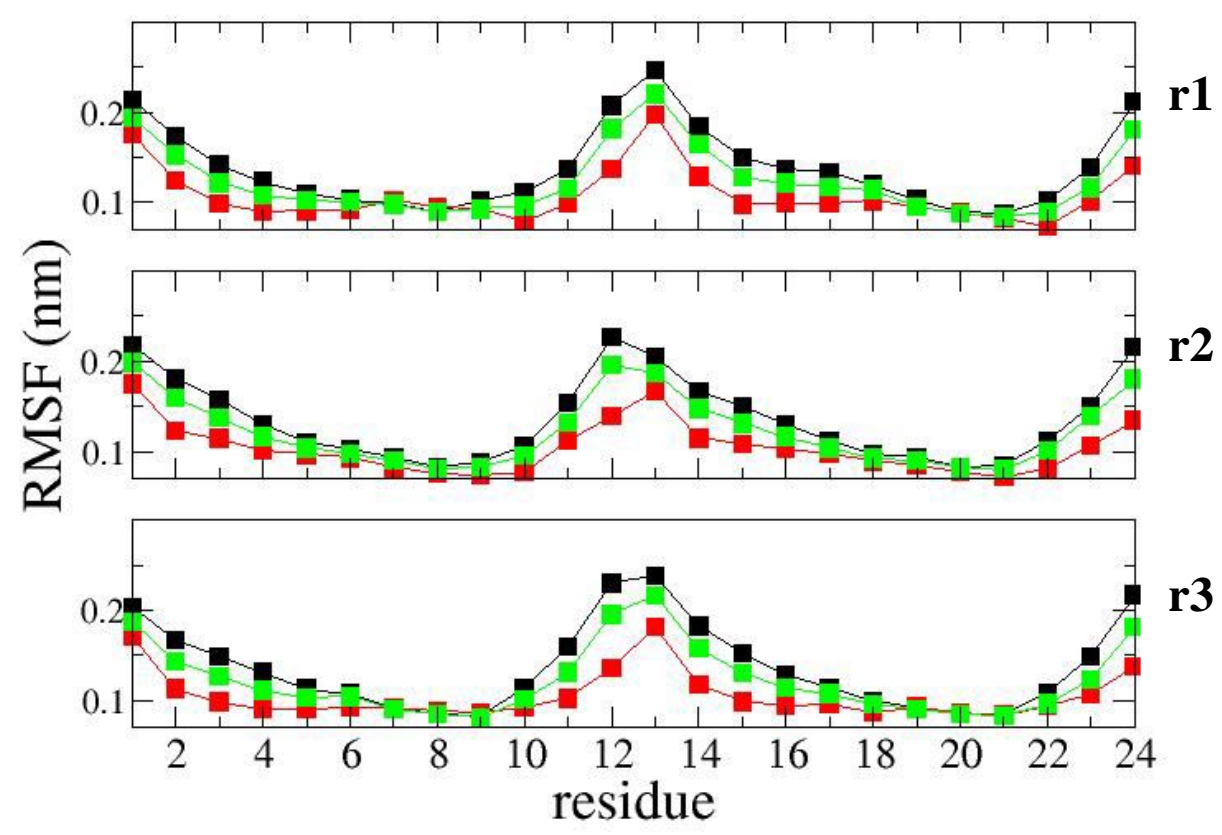

Figure 2SI. RMSF per residue for each duplex investigated. Black squares for backbone, red for base and green for sugar atoms. 

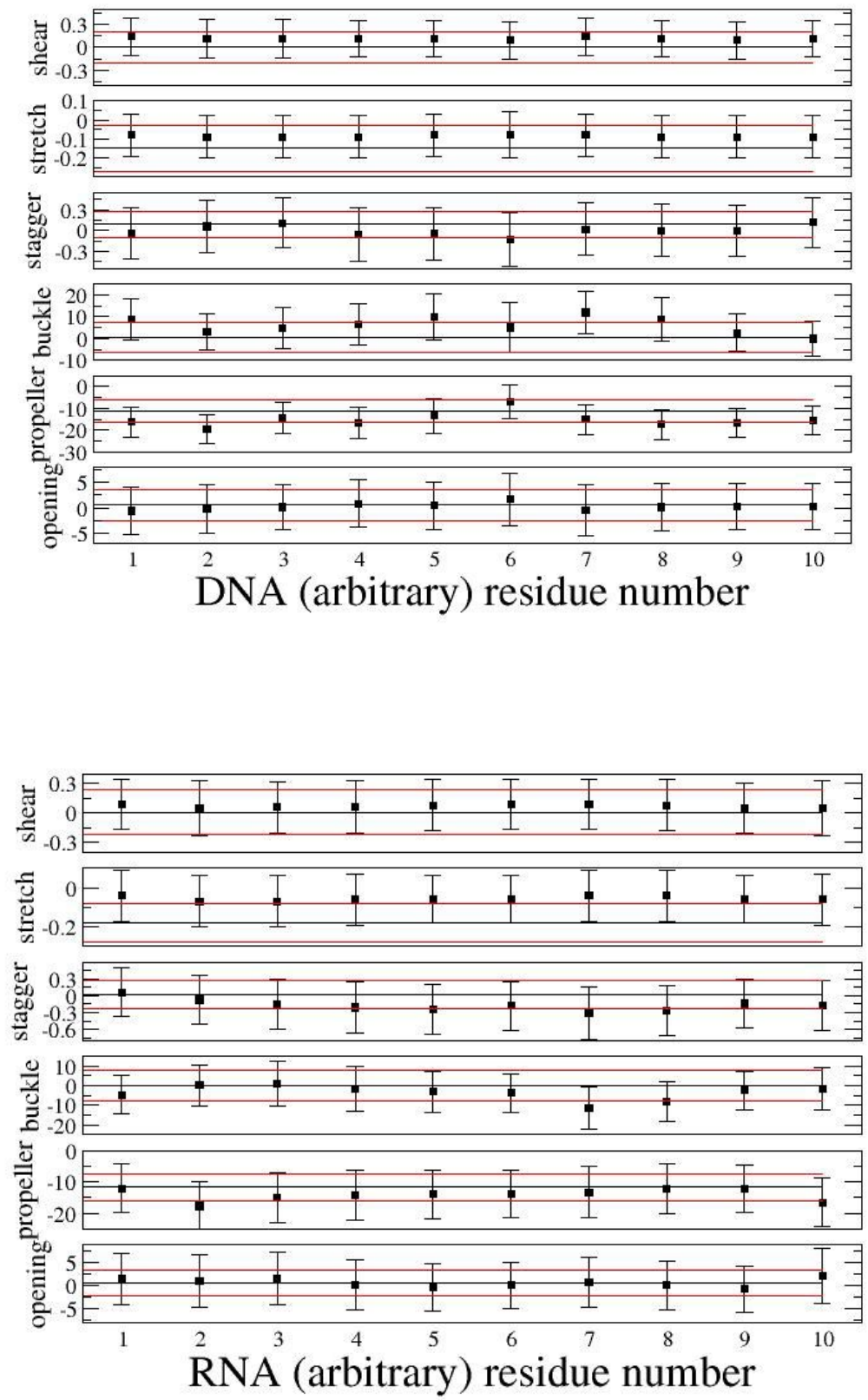

Figure 3SI. Comparison of the MD averaged base pair parameters (black squares, bars as standard deviation) and the averages from a statistical analysis of high resolution X-ray structures ${ }^{24}$ (black line represents the average, red lines 1 standard deviation displacements from the average). Note that comparison for RNA is made with parameters from A-DNA structures ${ }^{24}$. 

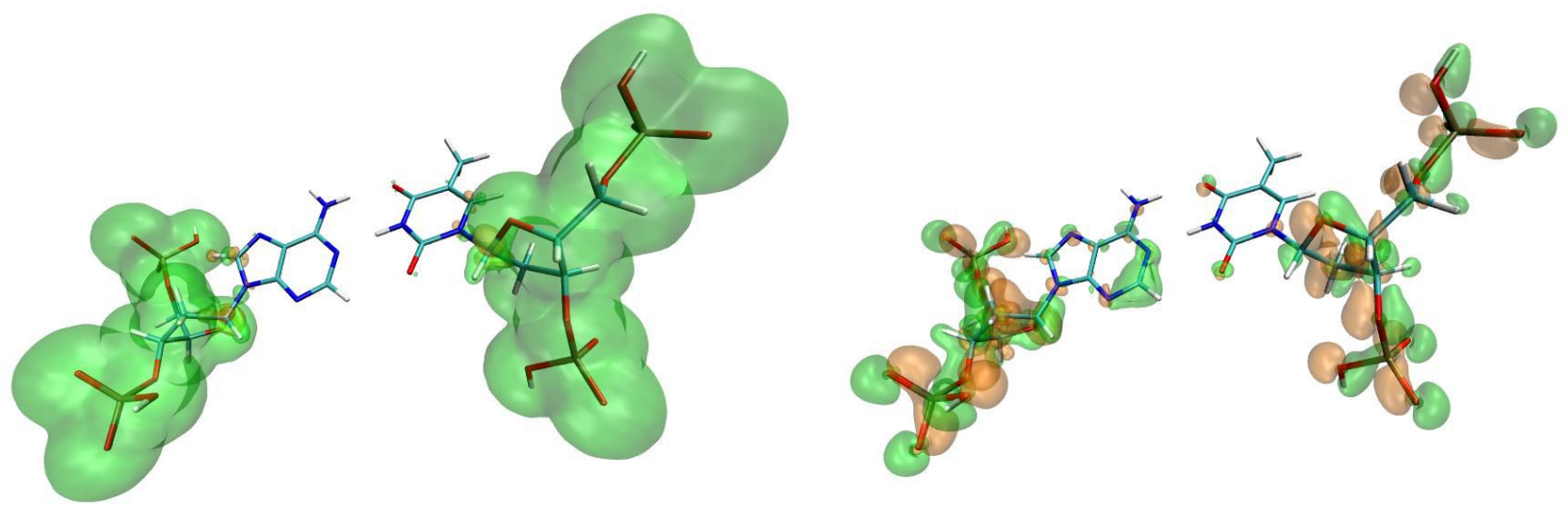

Figure 4SI. Left: Electronic density difference between the A:T nucleotide and the isolated A:T bases pair. The isodensity surfaces at 0.005 and at -0.005 e $\AA^{-3}$ are plotted in green and orange color, respectively. Right: Shielding density difference between the A:T nucleotide and the isolated A:T bases pair. The isoshielding density surfaces at 0.005 and at $-0.005 \mathrm{ppm} \AA^{-3}$ are plotted in green and orange, respectively. In both pictures, the structure of the A:T nucleotide is superimposed to the isosurfaces. 